\title{
PENGGUNAAN MEDIA MATRAS LISTRIK UNTUK MENGASAH KECERDASAN PSIKOMOTORIK BAGI SISWA TK PERTIWI DESA SEKARAN
}

\author{
Anis Umi Khoirotunnisa ${ }^{1),}$ Novi Mayasari ${ }^{2)}$, Nella Chandra Puspita ${ }^{3)}$ \\ Pendidikan Matematika, FPMIPA, IKIP PGRI Bojonegoro
}

\begin{abstract}
Abstrak
Media Matras LISTRIK (Literasi Sensori dan Motorik) merupakan suatu media permainan sekaligus media belajar yang diperuntukkan bagi siswa di tingkat pendidikan usia dini baik PAUD ataupun TK. Media Matras listrik ini di desain dengan kombinasi dari permainan melompat, berputar, menebak warna yang dalam gambarnya mengkombinasikan unsur angka dan huruf. Sesuai dengan nama Listrik yaitu sensori dan motorik maka desain dalam matras ini meliputi huruf abjad yang disusun dengan desain khusus untuk mampu menarik siswa, selain itu ditambahakan pula beberapa aksen untuk bermain anak. Psikomotorik merupakan ruang dimana yang memiliki keterkaitan dengan keterampilan (skill) atau kemampuan berbuat atau menghasilkan suatu pola setelah seseorang menerima pengalaman belajar baik secara formal maupun latihan mandiri. Hasil belajar psikomotor ini sebenarnya merupakan tahapan selanjutnya setelah kemampuan kongnitif (memahami sesuatu) dan dan hasil belajar afektif (yang baru tampak ketika sebuah perilaku menjadi kebiasaan dalam diri seseorang). Ranah psikomotor adalah berhubungan dengan kegiatan olah fisik, misalnya berlari, melompat ditempat, melukis, menari, mengayunkan anggota tangan dan kaki, dan sebagainya. Berdasarkan hasil kegiatan Pengabdian yang melibatkan siswa TK di desa sekaran yang telah dilakukan, anak-anak TK Pertiwi sangat antusias saat bermain mengikuti prosedur dalam permainan matras listrik. Selain itu, para guru di TK Pertiwi juga antusias mengarahkan siswanya untuk mencoba permainan, menyebutkan dengan keras huruf dan angka yang tersaji di media matras listrik. Hal ini menjadi indicator keberhasilan dimana siswa belajar dengan cara bersenang-senang melalui kemasan bermain, juga guru dapat berinovasi dengan memodifikasi media serupa.

Kata kunci : Media belajar, Literasi dan sensori, Psikomotorik.
\end{abstract}

\begin{abstract}
Matras LISTRIK Media (Sensory and Motoric Literacy) is a game media as well as learning media for students at the early childhood education level, either PAUD or kindergarten. This electric mat media is designed with a combination of jumping, spinning, guessing colors which combine elements of numbers and letters in the image. In accordance with the name Electricity, which is sensory and motoric, the design in this mat includes alphabet letters arranged in a special design to be able to attract students, besides that, some accents are also added for children's play. Psychomotor is a space where it is related to skills or the ability to act or produce a pattern after a person receives formal learning experiences and independent training. This psychomotor learning outcome is actually the next stage after the cognitive ability (understanding something) and affective learning outcomes (which only appear when a behavior becomes a habit in a person). The psychomotor domain is related to physical activity, for example running, jumping on the spot, painting, dancing, swinging the limbs, and so on. Based on the results of the Community Service activities involving kindergarten students in the current village, Pertiwi Kindergarten children are very enthusiastic when playing following the procedures in the electric mat game. In addition, teachers at Pertiwi Kindergarten are also enthusiastic in directing their students to try out the game, mentioning aloud the letters and numbers presented on the electric mat. This is an indicator of success where students learn by having fun through play packages, and teachers can innovate by modifying similar media.

Keyword : Learning Media, Literacy, sensori, Psikomotoric.
\end{abstract}

Correspondence author: Anis Umi Khoirotunnisa, anis.umi@ikippgribojonegoro.ac.id, Bojonegoro, Indonesia (c) (i) $\$$

This work is licensed under a CC-BY-NC 


\section{PENDAHULUAN}

Taman kanak-kanak (TK) adalah jenjang awal bagi anak-anak ( usia 3-6 tahun) dalam bentuk pendidikan formal yang kita sebut sekolah. Kurikulum pada taman Kanakkanak menfokuskan anak agar menerima dan memproses rangsangan panca indera untuk membantu pertumbuhan dan perkembangan jasmani dan rohani agar anak memiliki bekal belajar untuk memasuki pendidikan lebih lanjut di sekolah Dasar. Di Taman kanakkanak siswa diberi kesempatan untuk belajar dan diberikan kurikulum pembelajaran yang sesuai dengan usia pada tiap-tiap tingkatanya. Siswa diajarkan mengenai agama, budi bahasa, berhitung, membaca (mengenal aksara dan ejaan), bernyanyi, bersosialisasi dalam lingkungan keluarga dan teman-teman sepermainanya, dan berbagai macam keterampilan lainya.

Tujuan utama pembelajaran di Tingkat Kanak-kanak adalah meningkatkan kreasi karya anak-anak serta menstimulus mereka untuk belajar mengenal ilmu pengetahuan melalui berbagai macam pendekatan nilai berbudi dan berbahasa, agama, sosial, kondisi emosi, fisik, motorik, pengetahuan berpikir, seni dan kemandirian. Semua dirancang sebagai upaya mengembangkan daya pikir dan peranan anak dalam hidupnya. Anak usia 3-6 tahun pada tahapan periode berpikir dan bertindak sensitif atau masa peka. Masa yang diperuntukkan perangsangan bagi fungsi tubuh tertentu, diarahkan, agar perkembangan fisik dan mental tidak terhambat. Misalnya kemampuan berbicara. Jika tidak dilakukan proses rangsangan, anak menjadi tidak terlatih dan kesulitan bicara, diperlukan kebiasaan pelatihan kosa kata melalui metode bercerita dan mengenalkan kata. Pada periode ini anak harus didorong untuk mengutarakan antusiasme dari apa yang dilihat, didengar, dan dirasakan. Tujuanya: anak mampu mengembangkan prakarsa, daya kreatif, dan hal-hal produktif dalam bidang yang disenanginya.

Menurut Jean Peaget, ahli psikologi pendidikan dari swiss dalam (Ahmad Susanto, 2011) tahap pembagian perkembangan kognitif anak disebut memiliki empat periode. Periode pertama adalah tahap sensori-motor (0-2 tahun), dimana bayi menggunakan aktivasi motorik dan penginderaan dalam mengenal lingkunganya. Namun, fase penginderaan ini terbatas melalui respon sesaat atau refleksi sekilas, yang pengembangan upaya peniruan tindakan orang lain yang diamatinya. Karena masih bersifat meniru, pada tahap ini stimulus konkret perlu diberikan secara perlahan melalui pengulangan. Periode kedua adalah tahap pra operasional (2-7 tahun). Pada fase ini kemampuan berbahasa anak sudah baik, tapi masih egosentris, anak masih sulit melihat sesuatu dari perspektif berbeda. Misalnya, ketika mereka diperlihatkan sebuah gelas tinggi ramping dan sebuah gelas pendek dan lebar diisi dengan air sama banyaknya. Kebanyakan anak diusia ini menjawab ada lebih banyak air dalam gelas tinggi ramping.

Matras Listrik ( Literasi, Sensori dan motorik) merupakan alat peraga media pembelajaran yang diperuntukkan bagi siswa Taman Kanak-kanak sebagai media dalam pengenalan huruf dan angka dengan metode permainan sesuai dengan kemampuan psikomotorik anak. Menurut Gagne dalam (Ahmad Johari, 2008) pembelajaran adalah kemampuan seseorang yang tidak dipengaruhi secara signifikan oleh pertumbuhan usia, namun sebuah latihan. pembelajaran dapat diartikan sebagai sebuah kegiatan pembelajaran siswa. Siswa tidak hanya dituntut untuk mencapai hasil yang baik, tetapi juga dituntut untuk selalu terlibat aktif dalam proses pembelajaran. Perkembangan motorik pada umumnya dapat dibedakan menjadi dua yaitu perkembagan motorik kasar dan motorik halus (Sujiono et al., 2014). Motorik kasar adalah kemampuan gerak tubuh yang menggunakan otot-otot besar, sebagian besar atau seluruh Anggota tubuh dan 
diperlukan agar anak dapat memfungsikan otot- otot tubuhnya dengan benar seperti melatih kemampuan duduk dengan berbagai gaya, menendang, berlari, naik-turun tangga dan sebagainya.

Media pembelajaran yang tepat dalam pengggunaanya dapat meningkatkan penyambutan atau keterbukaan siswa menerima stimulus dari guru. Kemauan mulai tumbuh seiring dengan penyambutan dan penerimaan siswa terhadap rangsangan yang disuguhkan. Dengan adanya media pembelajaran, terlihat pada diri siswa kesediaan untuk menerima beban pelajaran, dan untuk itu perhatiannya akan tertuju kepada pelajaran yang diikutinya. Gaya belajar siswa dengan media pembelajaran akan memiliki kecenderungan penggunaan bentuk-bentuk representatif yang mewakili objek-objek yang dihadapi, baik itu berupa orang, benda, atau kejadian/peristiwa. Objek-objek itu direpresentasikan atau dihadirkan dalam diri seseorang melalui tanggapan, gagasan atau lambang, yang dalam psikologi semuanya merupakan sesuatu yang bersifat mental (Arsyad, 2014). Media pembelajaran Matras Listrik ini dapat digunakan untuk melatih kemampuan menghafalkan angka dan huruf sehingga menjadikan budaya literasi bagi siswa TK. Media pembelajaran Matras Listrik ini sebagai alat penunjang pemahaman memudahkan dalam menghitung dalam belajar siswa yang menarik, karena dapat disajikan dengan tampilan yang menarik dan dengan pengoperasian yang menyenangkan baik melalui perintah terstruktur ataupun permainan.

\section{METODE PELAKSANAAN}

Media Matras Listrik ini digunakan untuk pembelajaran di TK Pertiwi Desa sekaran kecamatan Kasiman Kabupaten Bojonegoro. Sekolah ini terpilih sebagai lokasi pengabdian berdasarkan pengisian survey dan hasil pengolahan lembar observasi yang dilakukan sebelumnya. Lembar survei ditujukan pada guru dan diperoleh informasi bahwa pembelajaran disekolah ini hanya bersifat ceramah, pembelajaran lebih banyak dilakukan di ruangan dan juga media belajar belum pernah menggunakan media serupa dengan matras listrik ini.

Strategi yang digunakan kebanyakan menggunakan alat permainan yang biasa dijumpai di took, berupa balok, pengenalan warna dan angka-angka. Pentingnya ragam media untuk pembelajaran di sekolah tingkat awal diungkapkan oleh (Ulfah, 2014) yang menyatakan pembelajaran pada usia taman kanak-kanak yang masih dalam lingkup anak usia dini sebagai langkah awal pembentukan perilaku dan watak pada anak. Dengan demikian, dipandang perlu untuk mengupayakan pembelajaran bermakna bagi anak dengan ragam media yang menyenangkan. Guru sebagai sumber belajar utama pada pembelajaran anak usia dini diupayakan menggunakan media agar efektif dan efisien (Francisco, 2013)

Metode yang digunakan dalam pembelajaran ini dengan ceramah dalam penyampaian prosedur permainan, kemudian adalah praktek penggunaan Media Matras Listrik untuk mengasah psikomotorik anak sesuai dengan gambar yang ada dalam media ini. Selain mengasah psikomotorik lewat melompat dan berputar sesuai dengan jalur dalam matras listrik ini, siswa juga mendapatkan pembelajaran literasi berupa menghafal angka dan huruf lewat permainan berjalan dan melompat sambil menyebutkan angka dan huruf yang diinjaknya. Berikut adalah gambar media media pembelajaran Matras Listrik serta penjelasanya. 


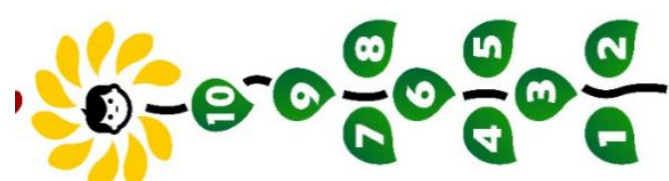 \\ Gambar 1 Pengenalan Angka 1 sampai 10}

Pada sesi pertama ini siswa diajak untuk mengenal angka dari 1-10 dengan cara menyenangkan akan membuat anak bersemangat. Cara mengimplementasikanya adalah dengan berjalan sesuai urutan angka yang ada. Kegiatan ini melatih konsentrasi siswa agar melangkah mengikuti alur yang ada dan sesuai dengan urutan angka dari yang paling kecil hingga terbesar. Jika tidak sesuai urutan, guru mempersilahkan siswa untuk mengulangi kembali dari awal sambil menyebutkan dengan keras angka yang diinjaknya. Ketika sampai diujung dimana digambarkan dengan bunga matahari mereka harus berhenti yang artinya tahap awal permainan berhasil dilalui.

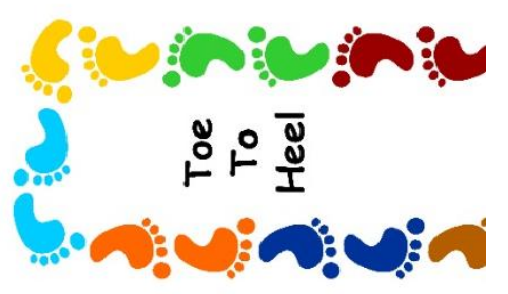

Gambar 2 Toe To Heel

Bagian kedua dari media matras listrik ini adalah dimana anak harus berjalan pada jalan setapak dimana letak kaki harus sesuai dengan gambar, artinya langkah kaki kanan dan kiri harus diperhatikan dengan benar.

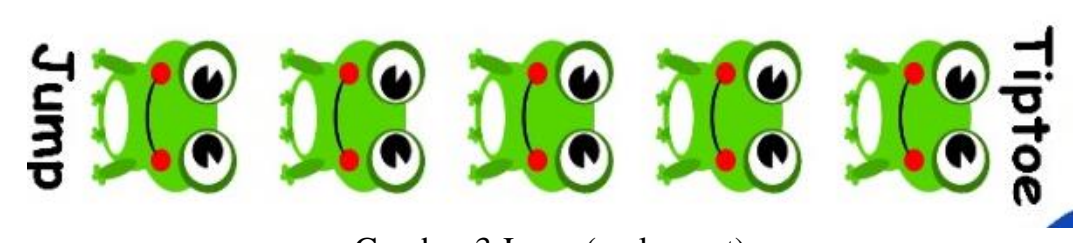

Gambar 3 Jump (melompat)

Pada sesi ini terdapat gambar katak yang bersiap untuk melompat. Anak- anak harus melompat tepat pada gambar katak. Kebiasaan anak TK yang suka melompat dapat terakomodir pada pembelajaran dengan media ini.

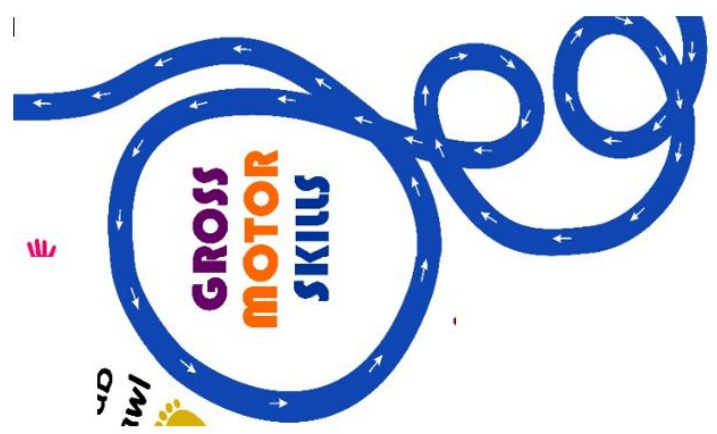

Gambar 4 Gross Motor Skills 
Pada sesi ini siswa diharuskan berjalan dengan berjinjit dan melalui lintasan sesuai dengan gambar dimana mereka harus berjalan luru, berputar dan berjalan dengan hatihati agar tidak terjatuh. Kegiatan ini melatih konsetrasi serta kekuatan otot kaki siswa.

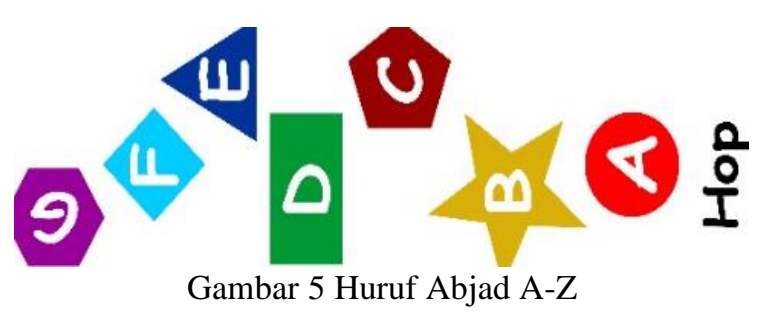

Sesi kegitan ke-5 ini media Matras Listrik menyajikan Huruf Abjad A sampai Z yang di desain dengan ragam warna dan bentuk bangun datar. Siswa diharuskan melompat mengikuti Alur huruf A-Z dengan mengucapkan dengan keras tepat saat menginjak huruf yang ada. Selain dapat belajar huruf, anak juga dapat belajar warna dan bentuk bangun datar yang ada.

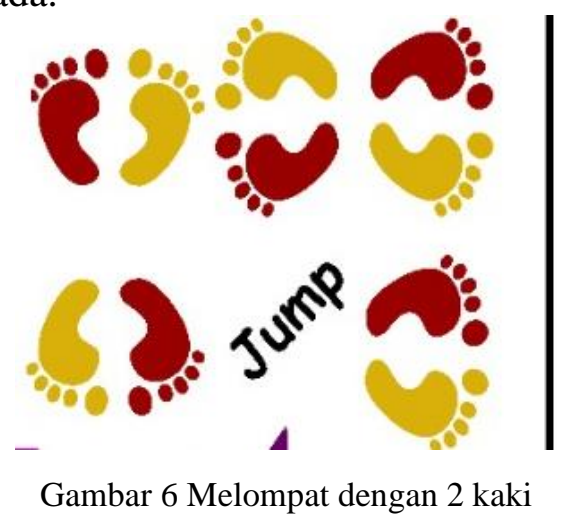

Gambar selanjutnya adalah gambar 2 kaki, dimana anak harus melompat berputar mengikuti arah gambar kaki yang ada. Jika pada sesi sebelumnya mereka melangkah sesuai gambar kaki kiri dan kanan, maka di sesi ini menggabungkan kemampuan menganalisis arah gerak dan kekuatan kaki dalam melompat.

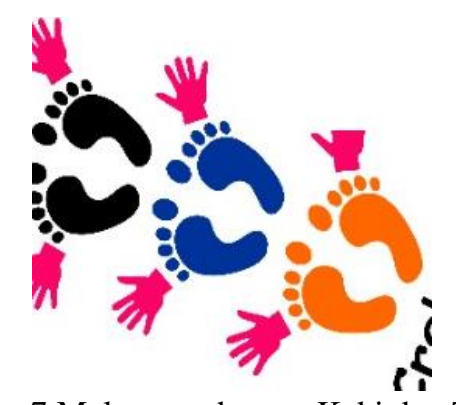

Gambar 7 Melompat dengan Kaki dan Tangan

Pada kegiatan ini siswa diajak untuk melompat tidak hanya menggunakan kaki, tapi juga dengan tangan, sehingga tidak hanya melatih kemampuan otot kaki untuk menopang tubuh, tapi juga tangan. Selain itu juga melatih konsentrasi siswa karena kegiatan dilakukan berbeda dalam tiap stepnya, yang tadinya melompat dengan dua kaki sekarang melompat dua kaki dan dua tangan. 


\section{HASIL DAN PEMBAHASAN}

Pelaksanaan kegiatan ini adalah pada tanggal 18 oktober 2019. Pelaksanaan kegiatan ini berupa implementasi pembelajaran menggunakan media pembelajaran Matras Listrik (Literasi, sensori dan motorik) untuk memaksimalkan ranah psikomotorik siswa. Kegiatan pengabdian ini bermanfaat tidak hanya bagi siswa dalam melatih motoric halus dimana kegiatan motoric halus merupakan satu kemampuan dasar dalam mengembangkan gerakan otot- otot halus pada tangan dengan koordinasi mata dan anggota tubuh lainya. Pada media Matras Listrik ini siswa diajak untuk belajar mengenal angka dan huruf, mengenal warna, gerakan aktif tangan dan kaki serta koordinasi fungsifungsi panca indera.

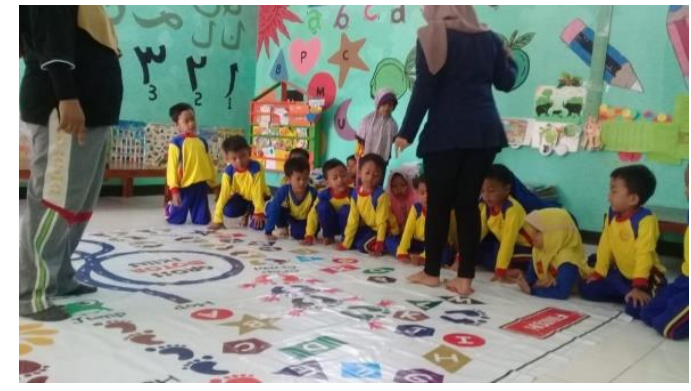

Gambar 8 Pengenalan alat permainan matras LISTRIK pada siswa

Kegiatan pertama adalah penjelasan mengenai tata cara penggunaan matras listrik. Anak-anak antusias mendengarkan penjelasan yang disampaikan tim pengabdi.

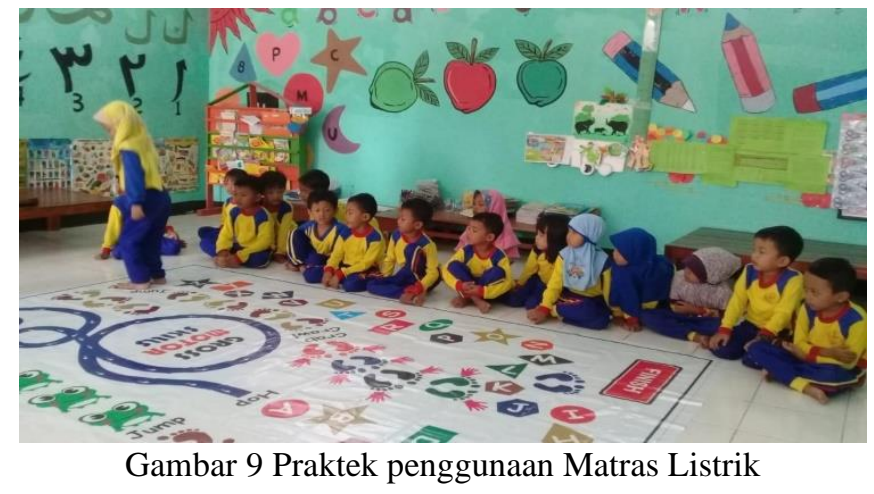

Kegiatan selanjutnya adalah praktek penggunaan Matras Listrik oleh siswa Taman Kanak-kanak desa Sekaran. Anak-anak bergantian mempraktekkan permainan mulai dari permainan angka, huruf melompat dan berputar mengikuti panduan.

Evaluasi bertujuan untuk melihat perkembangan program yang dilaksanakan berjalan lancer atau tidak. Tim pengabdian kepada masyarakat melakukan wawancara pada siswa untuk melihat respon siswa pada pembelajaran dengan media ini, selain itu wawancara juga dilakukan kepada guru-guru yang ada dilingkungan TK Pertiwi untuk mendapatkan masukan terkait penyempurnaan media pembelajaran ini. Pada Akhir kegiatan pengabdi melakukan sharing dengan guru dan siswa terkait perbaikan media Matras LISTRIK. Ibu Pastri selaku kepala sekolah TK Sekaran memberikan saran agar bahan yang digunakan bisa lebih baik lagi mengingat anak-anak yang aktif seringkali kurang berhati-hati saat melompat, sehingga bahan yang digunakan harus memperhatikan keamanan siswa, bahan lapisan bawah dibuat anti slip. 
Dari kegiatan Pengabdian Kepada Masyarakat di TK Pertiwi desa Sekaran Kecamatan Kasiman yang telah dilakukan, dapat dilihat antusiasme para siswa saat pertama melihat media matras listrik ini, warna-warna yang mencolok serta gambargambar yang ada didalamnya telah berhasil memusatkan perhatian siswa. Karakter siswa TK yang cenderung punya keingin tahuan yang tinggi pada hal baru membuat antusiasme siswa semakin besar.

Teori pendidikan bahwa siswa taman kanak-kanak menyatakan bahwa kegiatan yang diprogramkan untuk anak tidak boleh mengandung unsur paksaan. Selanjutnya menurut (HARTATI, 2017) menyatakan bahwa pertumbuhan perkembangan anak usia dini perlu diarahkan pada fisik, kognitif, sosio-emosional, kreativitas, dan Bahasa yang seimbang. Anak usia dini merupakan individu yang mengalami tumbuh kembang dengan pesat diberbagai aspek perkembangan. Oleh karena itu pendidikan anak sebelum masuk usia sekolah dasar harus mengacu pada prinsip bermain sambil belajar atau belajar seraya bermain, karena hamper seluruh` kegiatanya adalah bermain (Suyanto, 2005). Pada prinsipnya bermain mengandung rasa senang dan lebih mementingkan proses daripada hasil akhir (Yeni Rachmawati, S.Pd., M.Pd., Euis Kurniati, S.Pd., 2000). Dalam rangka mengoptimalkan tumbuh kembang anak, pendekatan pembelajaran yang terpusat pada anak yaitu pembelajaran melalui bermain, pembelajaran yang memungkinkan anak secara aktif berinteraksi dengan mengeksplorasi lingkunganya.

Pembelajaran yang dianggap paling tepat untuk anak pra-sekolah dasar adalah dengan model bermain. Karena sejatinya proses pembelajaran bagi anak adalah proses bermain yang merupakan fitrah dunianya. Melalui anak dapat mempelajari banyak hal, tanpa disadari oleh anak dan tanpa merasa terbebani. Melalui bermain anak dapat mengenal aturan, bersosialisasi, menempatkan diri, menata emosi, toleransi, kerjasama, mengalah, sportif, dan sikap-sikap positif lainya. Sulit sekali mencari pengganti kegiatan yang sepadan.dengan kegiatan bermain, termasuk kegiatan instrusional di kelas. Saat proses pembelajaran di kelas di TK Pertiwi terlihat anak yang tadinya belum mengenal seluruh huruf abjad, begitu antusias dan mengucapkan setiap huruf dalam tiap langkahnya. Hal ini tentunya membuatnya merasa lebih senang mempelajari huruf tanpa paksaan. Anak-anak yang suka melompat juga jadi senang karena boleh melompat dalam kelas, melompat sambil belajar bersama.

\section{SIMPULAN}

Simpulan dari kegiatan pengabdian kepada masyarakat ini adalah :

1. Media pembelajaran Matras Listrik (Literasi sensori dan motorik) adalah suatu media pembelajaran yang terdiri dari rangkaian desain angka, huruf dan permainan dengan gambar bentuk dan warna yang menarik sebagai media belajar literasi dan mengasah psikomotorik anak.

2. Media Matras Listrik ini adalah salah satu pilihan media yang dapat digunakan guru untuk membelajarkan menghafalkan huruf dan angka dengan cara yang menyenangkan.

\section{DAFTAR PUSTAKA}

Ahmad Johari, S. (2008). Teori Pembelajaran. Psikologi Pendidikan. 
Ahmad Susanto. (2011). Perkembangan anak usia dini. Jurnal Golden Age Hamzanwadi University.

Arsyad, A. (2014). Media Komunikasi dlama Pembelajaran. Jurnal Pembelajan.

Francisco, A. R. L. (2013). Pemanfaatan Media Pembelajaran Dalam Pembelajaran Pendidikan Jasmani Olahraga dan Kesehatan di Sekolah Dasar Negeri SeKecamatan Tepus Kabupaten Gunungkidul. Journal of Chemical Information and Modeling. https://doi.org/10.1017/CBO9781107415324.004

HARTATI, S. (2017). PENGEMBANGAN MODEL ASESMEN PERKEMBANGAN ANAK TAMAN KANAK- KANAK DI DKI JAKARTA. JPUD - Jurnal Pendidikan Usia Dini. https://doi.org/10.21009/jpud.111.02

Sujiono, B., Sumantri, M. S., \& Chandrawati, T. (2014). Hakikat Perkembangan Motorik Anak. Modul Metode Pengembangan Fisik.

Suyanto, S. (2005). Dasar-dasar Pendidikan Anak Usia Dini. Pendidikan.

Ulfah, M. (2014). PENGEMBANGAN PEMBELAJARAN AKTIF, INOVATIF, KREATIF, EFEKTIF DAN MENYENANGKAN (PAIKEM) DI SEKOLAH TAMAN KANAK-KANAK FULLDAY. In PAWIYATAN.

Yeni Rachmawati, S.Pd., M.Pd., Euis Kurniati, S.Pd., M. P. (2000). Strategi Pengembangan Kreativitas Pada Anak TK. In Strategi Pengembangan Kreativitas Pada Anak TK. 